\title{
THE PHOSPHOLIPID COMPOSITION OF HUMAN SERUM LIPOPROTEIN FRACTIONS SEPARATED BY ULTRACENTRIFUGATION *
}

\author{
BY GERALD B. PHILLIPS \\ (From the Departments of Biochemistry and Medicine, College of Physicians and Surgeonis, \\ Columbia University and Presbyterian Hospital, New York, N. Y.)
}

(Submitted for publication August 19, 1958; accepted November 13, 1958)

Since essentially all of the lipid of human serum appears to be present in the form of lipoprotein complexes which can be separated into distinct fractions by electrophoresis, chemical fractionation, or ultracentrifugation techniques, the composition of these lipoprotein fractions has attracted interest. Consequently, lipoprotein fractions have been analyzed for protein, cholesterol, cholesterol ester, triglyceride and total phospholipid content. The phospholipid of serum, however, is composed of several components which may have different functional roles. Since in previous studies $(1,2)$ it was shown that the principal serum phospholipid components, consisting of lecithin, sphingomyelin, lysolecithin, and phosphatidyl ethanolamine, could be separated by chromatography on silicic acid and then quantitated, the present investigation was carried out to determine the distribution of the individual phospholipids among different lipoprotein fractions. To isolate the lipoprotein fractions, the technique of ultracentrifugation at various serum densities $(3,4)$ as modified by Havel, Eder and Bragdon (5) was used. Lipoprotein fractions of density $<1.019,<1.063$ and $>1.063$ were then analyzed for the individual phospholipids, cholesterol, cholesterol ester and triglyceride.

\section{MATERIALS AND METHODS}

Serum samples were obtained in the fasting state from eight apparently healthy white adults (Table I).

Ultracentrifugation of the serum, begun within two to three hours after withdrawal, was accomplished according to the method of Havel, Eder and Bragdon (5). The samples were centrifuged at $105,000 \times \mathrm{G}$ at $15^{\circ} \mathrm{C}$. in the No. 40 rotor of a Model L Spinco ultracentrifuge. Each serum sample (except that from Subject E.Ri.) was divided into three parts and processed as follows: 1) Five to $8 \mathrm{ml}$. of serum was diluted to a density of 1.019 using a $\mathrm{NaCl}-\mathrm{KBr}$ solution of density 1.085 , centrifuged for 22

* This investigation was supported in part by a research grant (H-2907) from the National Heart Institute, Public Health Service, and in part by a gift from the American Heart Association. hours, and the top layer removed and extracted; 2) Four to $6 \mathrm{ml}$. of serum was diluted to a density of 1.063 using a $\mathrm{NaCl}-\mathrm{KBr}$ solution of density 1.346 , centrifuged for 22 hours, and the top and bottom layers separated and extracted; 3) Three to $5 \mathrm{ml}$. of untreated serum was extracted. In all of the samples, centrifugation resulted in a distinct layer at the top and bottom of the tube with a colorless zone about one-half the length of the tube in between. The upper layer of the 1.019 density tube was usually milky. The fractions were separated by slicing the tube with a Spinco tube slicer at approximately the center of the colorless zone.

The serum samples, which were not dialyzed before extraction, were extracted with methanol-chloroform $(1: 1, \mathrm{v} / \mathrm{v})$ and the extracts chromatographed on silicic acid columns $(1 \mathrm{Gm}$.) in order to determine the contents of the individual phospholipids, cholesterol, cholesterol ester and triglyceride (2). Certain of the extracts were also chromatographed on silicic acid-impregnated filter paper (Whatman No. 3) using 20 per cent methanol in chloroform $(v / v)$ as solvent. In addition, column fractions were hydrolyzed in $6 \mathrm{~N} \mathrm{HCl}$ at $110^{\circ} \mathrm{C}$. for 18 hours in a sealed tube and chromatographed on filter paper (Whatman No. 1) using butanol-acetic acid-water ( $4: 1: 4$, using butanol layer) as solvent for the nitrogenous components and acetone-water $(4: 1)$ as solvent for inositol. These paper chromatograms were developed by 1) spraying with ninhydrin in butanol, followed by heating at about $110^{\circ} \mathrm{C}$. for five minutes, 2) the phosphomolybdic acid stain of Chargaff, Levine and Green (6), and 3) the stain for inositol of Trevelyan (7) as modified by Anet and Reynolds (8).

The column fractions were analyzed for phosphorus by the method of Fiske and Subbarow (9), for cholesterol and cholesterol ester by the method of Schoenheimer and Sperry (10) as modified by Sperry and Webb (11), and for ester bonds by the method of Rapport and Alonzo (12).

\section{RESULTS}

The distribution of the total serum phospholipid among the three density fractions $(<1.019$, $<1.063,>1.063)$ of lipoproteins is recorded in Table I. The fraction with density $<1.063$ includes the fraction with density $<1.019$, and the values for a fraction with density 1.019 to 1.063 can be calculated by difference. Although there was considerable variation between subjects in the 
TABLE I

Distribution of serum phospholipids in density fractions

\begin{tabular}{|c|c|c|c|c|c|c|c|c|c|c|}
\hline \multirow{3}{*}{ Subject } & \multirow{3}{*}{ Sex } & \multirow{3}{*}{ Age } & \multicolumn{6}{|c|}{ Density of fraction } & \multirow{3}{*}{$\frac{\text { Recovery* }}{\%}$} & \multirow{3}{*}{$\begin{array}{c}\begin{array}{c}\text { Total } \\
\text { serum } \\
\text { lipid P }\end{array} \\
m M / L .\end{array}$} \\
\hline & & & \multicolumn{2}{|c|}{$<1.019$} & \multicolumn{2}{|c|}{$<1.063$} & \multicolumn{2}{|c|}{$>1.063$} & & \\
\hline & & & $m M / L$ & $\%$ total & $m M / L$ & $\%$ total & $m M / L$ & $\%$ total & & \\
\hline E. R. & $\mathbf{M}$ & 22 & 0.94 & 34.0 & 1.47 & 54 & 1.28 & 46 & 95 & 2.90 \\
\hline N. R. & $\mathbf{M}$ & 23 & 0.45 & 20.0 & 0.91 & 40 & 1.36 & 60 & 88 & 2.58 \\
\hline H. D. & $\mathbf{M}$ & 24 & 0.21 & 8.3 & 1.06 & 43 & 1.43 & 57 & 92 & 2.70 \\
\hline E. Ri. & $\mathbf{M}$ & 30 & & & 2.02 & 52 & 1.86 & 48 & 91 & 4.27 \\
\hline A. G. & $\mathbf{M}$ & 39 & 0.76 & 26.0 & 1.35 & 46 & 1.59 & 54 & 96 & 3.06 \\
\hline D. G. & 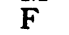 & 26 & 0.31 & 11.0 & 1.09 & 38 & 1.77 & 62 & 100 & 2.86 \\
\hline A. $\mathrm{R}$. & $\mathbf{F}$ & 31 & 0.28 & 8.4 & 1.42 & 43 & 1.88 & 57 & 100 & 3.30 \\
\hline R. D. & $\mathbf{F}$ & 31 & & & 1.62 & 45 & 1.99 & 55 & 90 & 4.01 \\
\hline Average & & & 0.49 & 18.0 & 1.37 & 45 & 1.65 & 55 & 94 & 3.21 \\
\hline
\end{tabular}

* Per cent recovery of total serum lipid $\mathrm{P}$ from 1.063 density tube after centrifugation.

percentage of total serum phospholipid in the fraction with density $<1.019$, the fraction with density $<1.063$ showed less individual variation. The mean phospholipid content was somewhat greater in the fraction with density $>1.063$ than in the fraction with density $<1.063$. The average recovery of phospholipid in the totaled separated fractions as compared to whole serum was 94 per cent.

The concentrations and relative distributions of the individual phospholipids of each density fraction are listed in Tables II through IV. The average relative distribution of the individual phospholipids of whole serum in these subjects was as follows: "cephalin," 4.8 per cent; lecithin, 68.2 per cent; sphingomyelin, 18.9 per cent ; and lysolecithin, 8.0 per cent. The "cephalin," although a mixture, is composed predominantly of ethanolamine-containing phospholipid (2). As can be seen in these tables; all four of the individual phospholipids were found in each density fraction. Moreover, the relative molar proportions of the individual phospholipids in the fraction with density $<1.019$ and in the fraction with density $<1.063$ were quite similar. But when comparing the values in these fractions to those of the fraction with density $>1.063$, striking differences were apparent. Although the relative amounts of "cephalin" and of lecithin were similar, there was relatively less sphingomyelin and more lysolecithin in the fraction with density $>1.063$. In fact, even though the fraction with density $>1.063$ included on an average a little more than half the total serum phospholipid, it contained about 40 per cent of the sphingomyelin and 75 per cent of the lysolecithin. To illustrate this point, the molar ratios of sphingomyelin-to-lecithin and of "cephalin"-to-sphingomyelin in the fractions with density $<1.063$ and density $>1.063$ are tabulated in Table V. From these figures, it is apparent that in the fraction with density $<1.063$, the mean molar sphingomyelin-to-lecithin ratio was twice, and the mean molar "cephalin"-to-sphingomyelin ratio about one-half, the value found in the frac-

TABLE II

Phospholipid composition of fraction with density $<1.019^{*}$

\begin{tabular}{|c|c|c|c|c|c|c|c|c|}
\hline \multirow{2}{*}{$\begin{array}{l}\text { Subject } \\
\\
\text { E. R. } \\
\text { N. R. } \\
\text { A. G. } \\
\text { A. R. }\end{array}$} & \multicolumn{2}{|c|}{ “Cephalin" } & \multicolumn{2}{|c|}{ Lecithin } & \multicolumn{2}{|c|}{ Sphingomyelin } & \multicolumn{2}{|c|}{ Lysolecithin } \\
\hline & $\begin{array}{c}m M / L \\
0.043 \\
0.030 \\
0.038 \\
0.018\end{array}$ & $\begin{array}{c}\text { \% total } \dagger \\
4.6 \\
6.6 \\
5.0 \\
6.4\end{array}$ & $\begin{array}{c}m M / L . \\
0.59 \\
0.31 \\
0.50 \\
0.19\end{array}$ & $\begin{array}{c}\% \text { total } \dagger \\
62.6 \\
68.8 \\
66.1 \\
67.4\end{array}$ & $\begin{array}{c}m M / L \\
0.26 \\
0.09 \\
0.18 \\
0.06\end{array}$ & $\begin{array}{c}\text { \% total } \dagger \\
27.2 \\
19.9 \\
23.8 \\
21.4\end{array}$ & $\begin{array}{c}m M / L \\
0.053 \\
0.021 \\
0.039 \\
0.014\end{array}$ & $\begin{array}{c}\text { \% total }+ \\
5.6 \\
4.7 \\
5.1 \\
5.0\end{array}$ \\
\hline Average & 0.032 & 5.7 & 0.40 & 66.2 & 0.15 & 23.1 & 0.032 & 5.1 \\
\hline
\end{tabular}

* Samples on other subjects either not done or too inaccurate because of small quantity.

$\dagger$ Per cent of total phospholipid of this fraction. 
PHOSPHOLIPID COMPOSITION OF HUMAN SERUM LIPOPROTEIN

TABLE III

Phospholipid composition of fraction with density $<1.063$

\begin{tabular}{|c|c|c|c|c|c|c|c|c|}
\hline \multirow[t]{2}{*}{ Subject } & \multicolumn{2}{|c|}{ "Cephalin" } & \multicolumn{2}{|c|}{ Lecithin } & \multicolumn{2}{|c|}{ Sphingomyelin } & \multicolumn{2}{|c|}{ Lysolecithin } \\
\hline & $m M / L$ & $\%$ total* & $m M / L$ & $\%$ total* & $m M / L$ & $\%$ total* & $m M / L$ & $\%$ total* \\
\hline E. R. & 0.068 & 4.6 & 0.98 & 66.4 & 0.37 & 25.4 & 0.053 & 3.6 \\
\hline N. R. & 0.047 & 5.2 & 0.62 & 67.9 & 0.21 & 22.6 & 0.040 & 4.4 \\
\hline H. D. & 0.053 & 5.0 & 0.70 & 65.6 & 0.28 & 26.4 & 0.031 & 2.9 \\
\hline E. Ri. & $t$ & $t$ & 1.35 & 66.6 & 0.51 & 25.2 & 0.089 & 4.4 \\
\hline A. G. & 0.055 & 4.1 & 0.89 & 66.0 & 0.34 & 25.1 & 0.065 & 4.8 \\
\hline D. G. & 0.048 & 4.4 & 0.71 & 64.8 & 0.29 & 26.2 & 0.051 & 4.7 \\
\hline A. R. & 0.051 & 3.6 & 0.93 & 65.3 & 0.39 & 27.1 & 0.058 & 4.1 \\
\hline R. D. & 0.063 & 3.9 & 1.10 & 67.8 & 0.40 & 24.6 & 0.062 & 3.8 \\
\hline Average & 0.056 & 4.4 & 0.91 & 66.3 & 0.35 & 25.3 & 0.056 & 4.1 \\
\hline
\end{tabular}

* Per cent of total phospholipid of this fraction.

† Sample lost.

tion with density $>1.063$. The mean molar lysolecithin-to-lecithin ratio in the fraction with density $>1.063$ was almost three times that in the fraction with density $<1.063$.

The ratios of free-to-total cholesterol and of cholesterol-to-phospholipid found in the separate fractions were similar to those reported by Bragdon, Havel and Boyle (13), and are not recorded here. Nonphospholipid ester, presumably triglyceride, was present in all of the fractions, but about 90 per cent was present in the fraction with density $<1.063$ and 10 per cent in the fraction with density $>1.063$.

The following three density fractions of serum from an apparently healthy nonfasting adult male were prepared according to the method of Havel, Eder and Bragdon (5) and chromatographed on silicic acid columns : 1) $<1.019,2) 1.019$ to 1.063 , and 3) $>1.063$. Column fractions were then analyzed for phospholipid constituents by the use of paper chromatography. Since the acid hydroly- sate of the second peak material (lecithin) of whole serum extract showed only one major constituent by paper chromatography (2), this peak material was not analyzed in the individual density fractions. Acid hydrolysates of the first peak material ("cephalin") of each density fraction and of the first peak material of whole serum extract (2) produced similar chromatograms. By far the predominating ninhydrin-reacting spot had the same Rf as ethanolamine. Fainter ninhydrin-reacting spots were evident, one with the Rf of serine, but no spots staining with the phosphomolybdic acid method were found. Acid hydrolysates of the "cephalin" peak material of each of the fractions also showed a spot with the $\mathrm{Rf}$ and staining properties of inositol.

Acid hydrolysates of the third peak material (sphingomyelin) of each of the three fractions likewise produced chromatograms similar to the third peak material acid hydrolysate of whole serum extract (2), showing two spots staining

TABLE IV

Phospholipid composition of fraction with density $>1.063$

\begin{tabular}{|c|c|c|c|c|c|c|c|c|}
\hline \multirow[t]{2}{*}{ Subject } & \multicolumn{2}{|c|}{ "Cephalin" } & \multicolumn{2}{|c|}{ Lecithin } & \multicolumn{2}{|c|}{ Sphingomyelin } & \multicolumn{2}{|c|}{ Lysolecithin } \\
\hline & $m M / L$ & $\%$ total* & $m M / L$ & $\%$ total* & $m M / L$ & $\%$ total* & $m M / L$ & $\%$ total* \\
\hline E. R. & 0.063 & 4.8 & 0.86 & 67.4 & 0.17 & 12.9 & 0.19 & 14.8 \\
\hline N. R. & 0.061 & 4.5 & 0.94 & 69.2 & 0.16 & 11.9 & 0.20 & 14.5 \\
\hline H. D. & $t$ & $t$ & 1.02 & 71.0 & 0.21 & 14.4 & 0.12 & 8.3 \\
\hline E. Ri. & 0.110 & 5.9 & 1.32 & 71.1 & 0.22 & 11.9 & 0.21 & 11.1 \\
\hline A. G. & 0.080 & 5.0 & 1.11 & 69.6 & 0.21 & 13.1 & 0.19 & 12.2 \\
\hline D. G. & 0.106 & 6.0 & 1.19 & 67.0 & 0.27 & 15.1 & 0.21 & 11.9 \\
\hline A. R. & 0.079 & 4.2 & 1.39 & 73.6 & 0.28 & 14.9 & 0.14 & 7.2 \\
\hline R. D. & 0.117 & 5.9 & 1.40 & 70.4 & 0.28 & 14.3 & 0.19 & 9.4 \\
\hline Average & 0.088 & 5.2 & 1.15 & 69.9 & 0.23 & 13.6 & 0.18 & 11.2 \\
\hline
\end{tabular}

* Per cent of total phospholipid of this fraction.

† Sample lost. 
TABLE V

Molar phospholipid ratios in density fractions

\begin{tabular}{lccccc}
\hline \hline & \multicolumn{2}{c}{ Sphingomyelin/Lecithin } & & \multicolumn{2}{c}{ “Cephalin”/Sphingomyelin } \\
\cline { 2 - 3 } \cline { 6 - 6 } Subject & $<1.063$ & $>1.063$ & & $<1.063$ & $>1.063$ \\
\hline E. R. & 0.38 & 0.19 & & 0.18 & 0.37 \\
N. R. & 0.33 & 0.17 & & 0.23 & 0.38 \\
H. D. & 0.40 & 0.20 & & 0.19 & \\
E. Ri. & 0.38 & 0.17 & & & 0.49 \\
A. G. & 0.38 & 0.19 & & 0.16 & 0.38 \\
D. G. & 0.40 & 0.23 & & 0.17 & 0.40 \\
A. R. & 0.41 & 0.20 & & 0.13 & 0.28 \\
R. D. & 0.36 & 0.20 & & 0.16 & 0.41 \\
Average & 0.38 & 0.19 & & 0.17 & 0.39 \\
& & & & & \\
\hline
\end{tabular}

with the phosphomolybdic acid method, one with the mobility of choline and a much smaller one, which is unidentified, and several minor ninhydrinreacting components.

Paper chromatography of acid hydrolysates of the last peak material (lysolecithin) of each of the three fractions showed one spot with the phosphomolybdic acid stain with the mobility of choline and several lesser ninhydrin-reacting components. These ninhydrin-reacting components were relatively more prominent than those seen with acid hydrolysates of the last peak material from whole serum extract, perhaps due to heavier nitrogenous contamination. To obtain further evidence that the last peak material was composed predominantly of lysolecithin, the unhydrolyzed last peak material of each fraction was also chromatographed on silicic acid-impregnated filter paper and showed a pattern similar to that of the last peak material of whole serum extract (2), i.e., three spots staining with the phosphomolybdic acid method, the major one with the $\mathrm{Rf}$ of lysolecithin and two much smaller ones with the Rf's of lecithin and sphingomyelin, respectively.

\section{DISCUSSION}

The ultracentrifugation method employing flotation for the separation of serum lipoprotein fractions was used because of its relative simplicity and accuracy. The composition of the lipoprotein fractions of human serum obtained by this method and by other methods has been compared $(5,14)$. On paper electrophoresis, the fraction with density $<1.063$ migrates as beta globulin and the fraction with density $>1.063$ as alpha globulin (5). On zone electrophoresis, however, the frac- tion with density $<1.018$ has been found to migrate as alpha $_{2}$ globulin, although material migrating as alpha ${ }_{2}$ globulin has also been found in some instances in higher density fractions (15).

Chromatographic analysis of three fractions, with densities of $<1.019,1.019$ to 1.063 , and $>1.063$, for the individual phospholipids in the present study revealed that all of the phospholipids identified were present in each of the three fractions. For example, acid hydrolysis of the "cephalin" produced ethanolamine, inositol and minor ninhydrin-reacting components in approximately the same relative amounts in each density fraction. Since each density fraction may contain a mixture of lipoproteins, however, the possibility that different lipoproteins contain different mixtures of phospholipids or even single phospholipids cannot be excluded.

When comparing the density fractions with regard to the relative quantities of the individual phospholipids present, however, definite differences were apparent. The values in the fractions with density $<1.019$ and $<1.063$ were quite similar but differed from those in the fraction with density $>1.063$. These differences were noted only for sphingomyelin and lysolecithin, as the relative amounts of "cephalin" and lecithin in the fractions with density $<1.063$ and $>1.063$ were similar. The molar sphingomyelin-to-lecithin ratio in the fraction with density $<1.063$ was two times that in the fraction with density $>1.063$, with little variation between subjects (Table V). The molar "cephalin"-to-sphingomyelin ratio in the fraction with density $<1.063$, on the other hand, was approximately one-half that found in the fraction with density $>1.063$, indicating that the molar "cephalin"to-lecithin ratio was similar in both fractions. The molar lysolecithin-to-lecithin ratio in the fraction with density $>1.063$ was almost three times that in the fraction with density $<1.063$, and this heavier fraction contained about three-fourths of the total serum lysolecithin. It has been found, moreover, that most of the lysolecithin in the fraction with density $>1.063$ is concentrated in a fraction with density $>1.210$ (16). The molar "cephalin"-to-sphingomyelin and lysolecithin-tolecithin ratios showed greater variation between subjects possibly because of the larger errors involved in the determination of "cephalin" and lysolecithin. 
This difference in sphingomyelin-to-lecithin ratio in the two large groups of serum lipoproteins has been noted by Steele and Kayden (17). Using electrophoresis on starch and determining the individual phospholipid contents by differential hydrolysis, these investigators found that the molar sphingomyelin-to-lecithin ratio was three times as great in the $\beta$ - as in the $\alpha$-lipoprotein fraction. The markedly greater variability in this ratio between subjects in their study as compared to the present study, however, suggests that their methods were less accurate.

The free-to-total-cholesterol and cholesterol-tophospholipid ratios found in the three density fractions were similar to those reported by Bragdon, Havel and Boyle (13). About 90 per cent of the total nonphospholipid ester, presumably triglyceride, was found in the fraction with density $<1.063$ and 10 per cent in the fraction with density $>1.063$.

\section{SUM MARY}

Serum lipoprotein fractions of density $<1.019$, 1.019 to 1.063 , and $>1.063$ from an apparently healthy nonfasting adult male were separated by ultracentrifugation and analyzed for the individual phospholipids using chromatography on both silicic acid columns and paper. All of the phospholipids and possible phospholipid constituents identified were found in each of the three fractions.

Serum lipoprotein fractions of density $<1.019$, $<1.063$ and $>1.063$ from eight apparently healthy fasting adults were separated by ultracentrifugation and analyzed for the individual phospholipids, cholesterol, cholesterol ester and triglyceride, using chromatography on silicic acid columns. The relative proportions of the individual phospholipids in the fractions with density $<1.019$ and $<1.063$ were similar but differed from the values found in the fraction with density $>1.063$. In the fraction with density $<1.063$, the molar ratio of sphingomyelin-to-lecithin was twice, and of "cephalin"-to-sphingomyelin about one-half, the corresponding value found in the fraction with density $>1.063$. Both fractions, therefore, had similar molar "cephalin"-to-lecithin ratios. The molar lysolecithin-to-lecithin ratio of the heavier fraction was almost three times that of the lighter fraction, but there was much variation between subjects.

\section{REFERENCES}

1. Phillips, G. B. The isolation of lysolecithin from human serum. Proc. nat. Acad. Sci. (Wash.) 1957, 43, 566.

2. Phillips, G. B. The isolation and quantitation of the principle phospholipid components of human serum using chromatography on silicic acid. Biochim. biophys. Acta 1958, 29, 594.

3. Pedersen, K. O. On a low-density lipoprotein appearing in normal human plasma. J. phys. coll. Chem. 1947, 51, 156.

4. Lindgren, F. T., Elliott, H. A., and Gofman, J. W. The ultracentrifugal characterization and isolation of human blood lipids and lipoproteins, with applications to the study of atherosclerosis. J. phys. coll. Chem. 1951, 55, 80.

5. Havel, R. J., Eder, H. A., and Bragdon, J. H. The distribution and chemical composition of ultracentrifugally separated lipoproteins in human serum. J. clin. Invest. 1955, 34, 1345.

6. Chargaff, E., Levine, C., and Green, C. Techniques for the demonstration by chromatography of nitrogenous lipide constituents, sulfur-containing amino acids, and reducing sugars. J. biol. Chem. 1948, 175, 67.

7. Trevelyan, W. E., Procter, D. P., and Harrison, J. S. Detection of sugars on paper chromatograms. Nature (Lond.) 1950, 166, 444.

8. Anet, E. F. L. J., and Reynolds, T. M. Isolation of mucic acid from fruits. Nature (Lond.) 1954, 174, 930.

9. Fiske, C. H., and Subbarow, Y. The colorimetric determination of phosphorus. J. biol. Chem. 1925, 66, 375 .

10. Schoenheimer, R., and Sperry, W. M. A micromethod for the determination of free and combined cholesterol. J. biol. Chem. 1934, 106, 745.

11. Sperry, W. M., and Webb, M. A revision of the Schoenheimer-Sperry method for cholesterol determination. J. biol. Chem. 1950, 187, 97.

12. Rapport, M. M., and Alonzo, N. Photometric determination of fatty acid ester groups in phospholipides. J. biol. Chem. 1955, 217, 193.

13. Bragdon, J. H., Havel, R. J., and Boyle, E. Human serum lipoproteins. I. Chemical composition of four fractions. J. Lab. clin. Med. 1956, 48, 36.

14. Hillyard, L. A., Entenman, C., Feinberg, H., and Chaikoff, I. L. Lipide and protein composition of four fractions accounting for total serum lipoproteins. J. biol. Chem. 1955, 214, 79.

15. Kunkel, H. G., and Trautman, R. The $\alpha_{2}$ lipoproteins of human serum. Correlation of ultracentrifugal and electrophoretic properties. J. clin. Invest. 1956, 35, 641.

16. Phillips, G. B. Lipid composition of human serum lipoprotein fraction with density greater than 1.210. Proc. Soc. exp. Biol. (N. Y.) 1959. In press.

17. Steele, J. M., and Kayden, H. J. The nature of the phospholipids in human serum and atheromatous vessels. Trans. Ass. Amer. Phycns 1955, 68, 249. 